\title{
Akt Substrate of 160 kDa Dephosphorylation Rate Is Reduced in Insulin-Stimulated Rat Skeletal Muscle After Acute Exercise
}

\author{
E. B. ARIAS ${ }^{1}$, H. WANG ${ }^{1}$, G. D. CARTEE ${ }^{1,2,3}$ \\ ${ }^{1}$ Muscle Biology Laboratory, School of Kinesiology, University of Michigan, Ann Arbor, MI, \\ USA, ${ }^{2}$ Department of Molecular and Integrative Physiology, University of Michigan, Ann Arbor, \\ MI, USA, ${ }^{3}$ Institute of Gerontology, University of Michigan, Ann Arbor, MI, USA
}

Received January 4, 2017

Accepted July 21, 2017

On-line November 10, 2017

\begin{abstract}
Summary
Because greater Akt substrate of $160 \mathrm{kDa}$ (AS160) phosphorylation has been reported in insulin-stimulated skeletal muscles without improved Akt activation several hours post-exercise, we hypothesized that prior exercise would result in attenuated AS160 dephosphorylation in insulin-stimulated rat skeletal muscle. Epitrochlearis muscles were isolated from rats that were sedentary (SED) or exercised $3 \mathrm{~h}$ earlier ( $3 \mathrm{~h}$ postexercise; 3hPEX). Paired muscles were incubated with $\left[{ }^{3} \mathrm{H}\right]$-2-deoxyglucose (2-DG) without insulin or with insulin. Lysates from other insulin-stimulated muscles from SED or 3hPEX rats were evaluated using $\mathrm{AS} 160^{\text {thr642 }}$ and $A S 160^{\text {Ser588 }}$ dephosphorylation assays. Prior exercise led to greater 2-DG uptake concomitant with greater AS160 ${ }^{\text {Thr642 }}$ phosphorylation and a non-significant trend $(P=0.087)$ for greater $A S 160^{\text {Ser588 }}$. Prior exercise also reduced $\mathrm{AS} 160^{\text {Thr642 }}$ and $A S 160^{\text {Ser588 }}$ dephosphorylation rates. These results support the idea that attenuated AS160 dephosphorylation may favor greater AS160 phosphorylation post-exercise.
\end{abstract}

\section{Key words}

Insulin sensitivity • Glucose transport • TBC1D4

\section{Corresponding author}

G. D. Cartee, School of Kinesiology, University of Michigan, 401 Washtenaw Avenue, Ann Arbor, MI 48109-2214, USA. E-mail: gcartee@umich.edu

\section{Introduction}

One exercise session can substantially elevate subsequent insulin-stimulated glucose uptake by skeletal muscle (Cartee 2015a, Wojtaszewski et al. 2003). Earlier research indicates this improvement is not caused by elevated insulin signaling at proximal steps from insulin receptor binding to stimulation of the serine/threonine protein kinase Akt (Cartee 2015a, Castorena et al. 2014, Funai et al. 2009, Pehmoller et al. 2012) suggesting the mechanism may involve events distal to Akt. Akt substrate of $160 \mathrm{kDa}$ (AS160; also called TBC1D4) phosphorylation on $\mathrm{Thr}^{642}$ by Akt is crucial for insulinstimulated glucose transport (Cartee 2015b, Chen et al. 2011). Earlier research demonstrated that exercise can induce greater AS160 phosphorylation for hours post-exercise, and greater AS160 phosphorylation is implicated in the exercise-induced improvement of insulin sensitivity (Arias et al. 2007, Cartee 2015b, Castorena et al. 2014, Funai et al. 2009, Pehmoller et al. 2012). Given the evidence that exercise does not lead to subsequently elevated Akt activity in insulin-stimulated muscle, we hypothesized that exercise producing greater insulin-stimulated glucose uptake and AS160 phosphorylation would also attenuate AS160 dephosphorylation in rat muscle.

Memcode Reversible Protein Stain, bicinchoninic acid protein assay kits and Tissue Protein Extraction Reagent, T-PER were from Thermo Fisher (Pittsburgh, PA, USA). Luminata Forte Western HRP 
Substrate was from EMD Millipore (Billerica, MA, USA). Anti-phospho AS160 Thr642 (pAS160 Thr642), anti-phospho AS160 Ser588 (pAS160 ${ }^{\text {Ser588}) ~ a n d ~}$ anti-rabbit IgG horseradish peroxidase conjugate were from Cell Signaling Technology (Danvers, MA, USA).

Animal care procedures were approved by the University of Michigan Committee on Use and Care of Animals. Methods were performed in accordance with the guidelines from the Guide for the Care and Use of Laboratory Animals of the National Institutes of Health, USA. Male Wistar rats $(\sim 250 \mathrm{~g})$ had unlimited access to rodent chow until they were fasted at $17 \mathrm{~h}$ on the night before the experiment. Exercised rats swam in a barrel filled with water $\left(35^{\circ} \mathrm{C}\right.$; $\sim 45 \mathrm{~cm}$ depth; 6/barrel) for 4x30 min bouts with $5 \mathrm{~min}$ rest between bouts. Exercising rats were dried and returned to their cages without food for $\sim 3 \mathrm{~h}$, then anesthetized (intraperitoneal sodium pentobarbital, $50 \mathrm{mg} / \mathrm{kg}$ ) at the same time as sedentary controls (SED). Epitrochlearis muscles from SED and exercised ( $3 \mathrm{~h}$ post-exercise, $3 \mathrm{hPEX}$ ) rats were used for the analyses described below.

Isolated muscles underwent a two-step incubation in vials containing $2 \mathrm{ml}$ of media (gassed with $\left.95 \% \quad \mathrm{O}_{2}-5 \% \mathrm{CO}_{2}\right)$ in a shaking water-bath $\left(35^{\circ} \mathrm{C}\right)$. Incubation step 1 (30 min) was in KHB/BSA (Krebs Henseleit Buffer, KHB, with $0.1 \%$ bovine serum albumin, BSA) supplemented with $2 \mathrm{mM}$ sodium pyruvate and $6 \mathrm{mM}$ mannitol with or without $0.6 \mathrm{nM}$ insulin. Incubation step 2 (20 min) was in KHB/BSA with $0.1 \mathrm{mM}$ 2-deoxy-D-glucose, 2-DG, $(2.25 \mathrm{mCi} / \mathrm{mmol}$ $\left.{ }^{3} \mathrm{H}-2-\mathrm{DG}\right)$ and $9.9 \mathrm{mM}$ mannitol $(0.022 \mathrm{mCi} / \mathrm{mmol}$ ${ }^{14} \mathrm{C}$-mannitol), and the same insulin concentration as step 1. Muscles were freeze-clamped and stored at $-80^{\circ} \mathrm{C}$ until homogenized. A portion of muscle lysate was used to determine ${ }^{3} \mathrm{H}-2-\mathrm{DG}$ accumulation by liquid scintillation counting (Hansen et al. 1994). Another portion of the lysate was used to determine AS160 ${ }^{\text {Thr642 }}$ and $\mathrm{AS} 160^{\mathrm{Ser} 588}$ phosphorylation by immunoblotting as previously described (Castorena et al. 2014, Sharma et al. 2016) and summarized below.

Laemmli buffer was added to equal amounts of lysate protein, boiled and subjected to SDS-PAGE. Proteins were transferred to PVDF. Equal loading was confirmed by MemCode protein stain. Membranes were blocked, washed, incubated with secondary antibody, washed and incubated with enhanced chemiluminescence reagent. Protein bands quantified by densitometry were expressed relative to the normalized average of all samples on the blot.
Isolated muscles from other rats were used for a dephosphorylation assay. Muscles were incubated in vials containing $\mathrm{KHB} / \mathrm{BSA}$ with $2 \mathrm{mM}$ sodium pyruvate, $6 \mathrm{mM}$ mannitol and 0.6 or $30 \mathrm{nM}$ insulin (30 min with shaking and gassing, $35^{\circ} \mathrm{C}$ ). Immediately post-incubation, muscles were freeze-clamped and stored at $-80{ }^{\circ} \mathrm{C}$ until processed.

The AS160 dephosphorylation assay has been described (Sharma et al. 2016). Frozen muscles were rapidly homogenized in ice-cold buffer including protease inhibitors $(1 \mu \mathrm{g} / \mathrm{ml}$ leupeptin, $1 \mu \mathrm{g} / \mathrm{ml}$ pepstatin, $1 \mu \mathrm{g} / \mathrm{ml}$ aprotinin, and $1 \mathrm{mM}$ phenylmethylsulfonyl fluoride) but without protein phosphatase inhibitors. An initial aliquot (20 $\mu 1 ; 0$ min time-point) was rapidly removed from each sample, immediately mixed with an equal volume of $2 \mathrm{X}$ SDS loading buffer, and heated $\left(95^{\circ} \mathrm{C}, 3 \mathrm{~min}\right)$. The remaining samples were incubated $\left(37^{\circ} \mathrm{C}\right)$ and aliquots $(20 \mu \mathrm{l})$ were removed $(5,10,20,30$, 40 and $50 \mathrm{~min}$ ), rapidly mixed with an equal volume of 2X SDS loading buffer and heated $\left(95^{\circ} \mathrm{C}, 3 \mathrm{~min}\right)$. Samples were subjected to SDS-PAGE and immunoblotting for $\mathrm{AS} 160^{\text {Thr642 }}$ and $\mathrm{AS} 160^{\mathrm{Ser} 588}$ phosphorylation.

For 2-DG uptake and AS160 phosphorylation of muscles incubated \pm insulin, two-way ANOVA was used to identify significant main effects. Holm-Sidak post-hoc analysis was used to identify the source of significant variance. For the dephosphorylation assay, differences were evaluated by two-tailed t-test.

There were significant main effects of insulin $(\mathrm{P}<0.001)$ and exercise $(\mathrm{P}<0.01)$ on $2-\mathrm{DG}$ uptake (Fig. 1A). Post-hoc analysis identified a significant effect of insulin versus no insulin on 2-DG uptake in SED $(\mathrm{P}<0.05)$ and 3hPEX $(\mathrm{P}<0.001)$ groups, and 2-DG uptake in insulin-stimulated muscles was greater for $3 \mathrm{hPEX}$ versus $\mathrm{SED}(\mathrm{P}<0.01)$. There were significant main effects of insulin $(\mathrm{P}<0.001)$ and exercise $(\mathrm{P}<0.001)$ for AS $160^{\text {Thr642 }}$ phosphorylation (Fig. 1B). Post-hoc analysis detected a significant insulin effect on $\mathrm{AS}_{160} 0^{\text {Thr642 }}$ phosphorylation in SED $(\mathrm{P}<0.001)$ and 3hPEX $(\mathrm{P}<0.001)$ muscles. AS160 ${ }^{\text {Thr642 }}$ phosphorylation was significantly greater in $3 \mathrm{hPEX}$ versus SED muscles without insulin $(\mathrm{P}<0.05)$ or with insulin $(\mathrm{P}<0.05)$. There was a significant main effect of insulin $(\mathrm{P}<0.005)$ and a trend for a main effect of exercise $(\mathrm{P}=0.087)$ for $\mathrm{AS} 160^{\mathrm{Ser} 588}$ phosphorylation (Fig. 1C). Post-hoc analysis detected a significant insulin effect on AS160 $0^{\mathrm{Ser} 588}$ phosphorylation in SED $(\mathrm{P}<0.05)$ and 3hPEX $(\mathrm{P}<0.01)$ muscles. The dephosphorylation assay results from muscles incubated 
A

\section{2-Deoxyglucose Uptake}

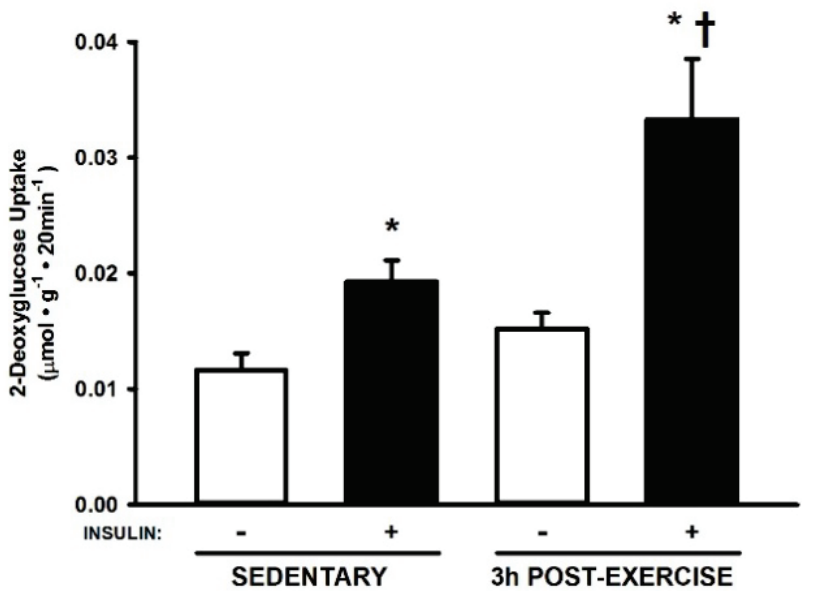

$\mathbf{B}$

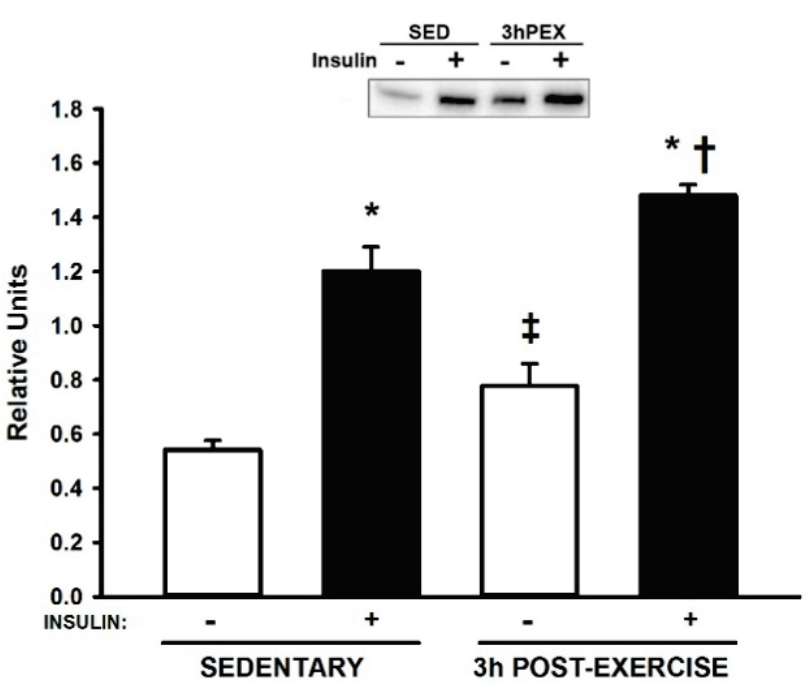

C

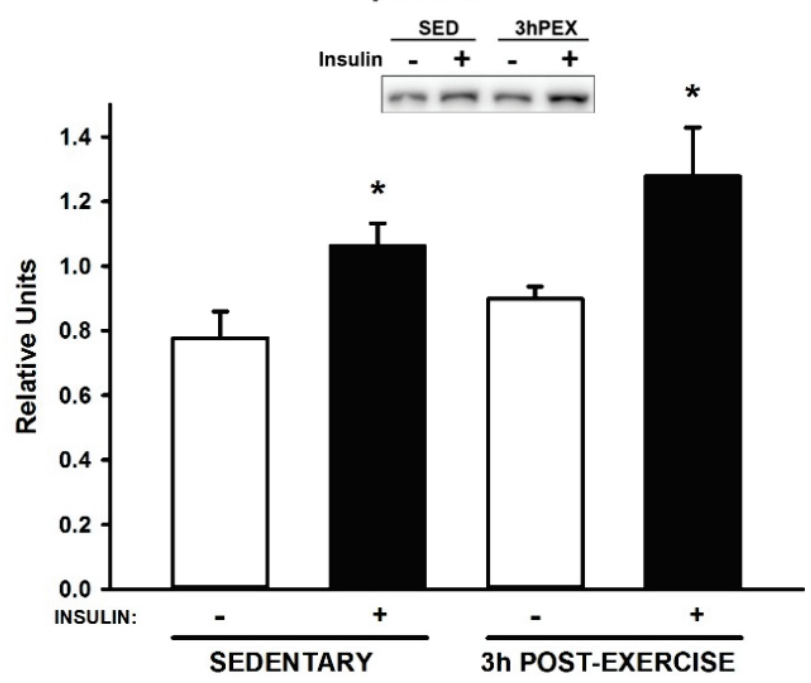

with $0.6 \mathrm{nM}$ insulin demonstrated AS160 ${ }^{\text {Thr642 }}(\mathrm{P}<0.001$ at 5 and $10 \mathrm{~min} ; \mathrm{P}<0.005$ at $20 \mathrm{~min} ; \mathrm{P}<0.05$ at 30,40 and $50 \mathrm{~min}$; Fig. 2A) and AS160 ${ }^{\mathrm{Ser} 588}$ phosphorylation for
Fig. 1. (A) There were significant main effects of insulin $(P<0.001)$ and exercise $(P<0.01)$ on 2 -DG uptake. $* P<0.05$, Sedentary or $3 \mathrm{hPEX}$ muscles with insulin versus muscles without insulin; ${ }^{+} \mathrm{P}<0.05$, 3hPEX muscles with insulin versus Sedentary muscles with insulin. (B) There were significant main effects of insulin $(P<0.001)$ and exercise $(P<0.001)$ on $A S 160^{\text {Thr642 }}$ phosphorylation. $* \mathrm{P}<0.001$, Sedentary muscles with insulin versus Sedentary muscles without insulin and 3hPEX muscles with insulin versus $3 \mathrm{hPEX}$ muscles without insulin; ${ }^{*} \mathrm{P}<0.05$, 3hPEX muscles without insulin versus Sedentary muscles without insulin; ${ }^{\dagger} \mathrm{P}<0.05$, 3hPEX muscles with insulin versus Sedentary muscles with insulin. (C) There was a significant main effect of insulin $(P<0.005)$ and a trend for a main effect of exercise $(\mathrm{P}=0.087)$ on $A S 160^{\mathrm{Ser} 588}$ phosphorylation. $* \mathrm{P}<0.05$, Sedentary muscles with insulin versus Sedentary muscles without insulin; $* \mathrm{P}<0.01$, 3hPEX muscles with insulin versus 3hPEX muscles without insulin. Values are expressed as mean $\pm S E M ; n=6-9$ per treatment.

3hPEX significantly exceeded $\mathrm{SED}$ values $(\mathrm{P}<0.005$ at 5 min; $\mathrm{P}<0.05$ at 10, 20 and $30 \mathrm{~min}$; Fig. 2B). However, using muscles incubated with $30 \mathrm{nM}$ insulin, there were no significant differences between $3 \mathrm{hPEX}$ versus SED for $\mathrm{AS} 160^{\text {Thr642 }}$ or $\mathrm{AS} 160^{\mathrm{Ser} 588}$ phosphorylation at any time-point (results not shown).

Because greater AS160 phosphorylation has been reported in insulin-stimulated muscles without greater Akt activation several hours post-exercise (Castorena et al. 2014, Funai et al. 2009, Pehmoller et al. 2012), we hypothesized that prior exercise would attenuate AS160 dephosphorylation in insulin-stimulated rat muscle. The dephosphorylation assay results for muscles stimulated with a physiologic insulin dose supported the hypothesis. Exercise reduced AS160 ${ }^{\text {Thr642 }}$ and $\mathrm{AS} 160^{\mathrm{Ser} 588}$ dephosphorylation in muscles that had been stimulated with the same insulin dose $(0.6 \mathrm{nM})$ as was used for glucose uptake assessment. Interestingly, no exercise-effect occurred in muscles stimulated with $30 \mathrm{nM}$ insulin. Perhaps this supraphysiologic insulin dose resulted in modifications in AS160 and/or phosphatases that masked the normal exercise-effect that was found in muscles exposed to a physiologic insulin concentration.

Consistent with previous studies (Cartee and Holloszy 1990, Castorena et al. 2014, Funai et al. 2009), prior exercise resulted in greater insulin-stimulated glucose uptake several hours after acute exercise versus SED. AS160 ${ }^{\text {Thr642 }}$ phosphorylation was also increased in insulin-stimulated muscles at $3 \mathrm{hPEX}$ versus SED, consistent with earlier research (Cartee 2015a, Castorena et al. 2014, Funai et al. 2009). Previous research detected greater muscle AS160 ${ }^{\text {Ser588 }}$ phosphorylation at $3 \mathrm{hPEX}$ versus SED (Castorena et al. 2014), and there was a trend for an exercise-effect on AS160 $0^{\text {Ser588 }}$ in this study. 
A pAS160 $0^{\text {Thr642 }}$
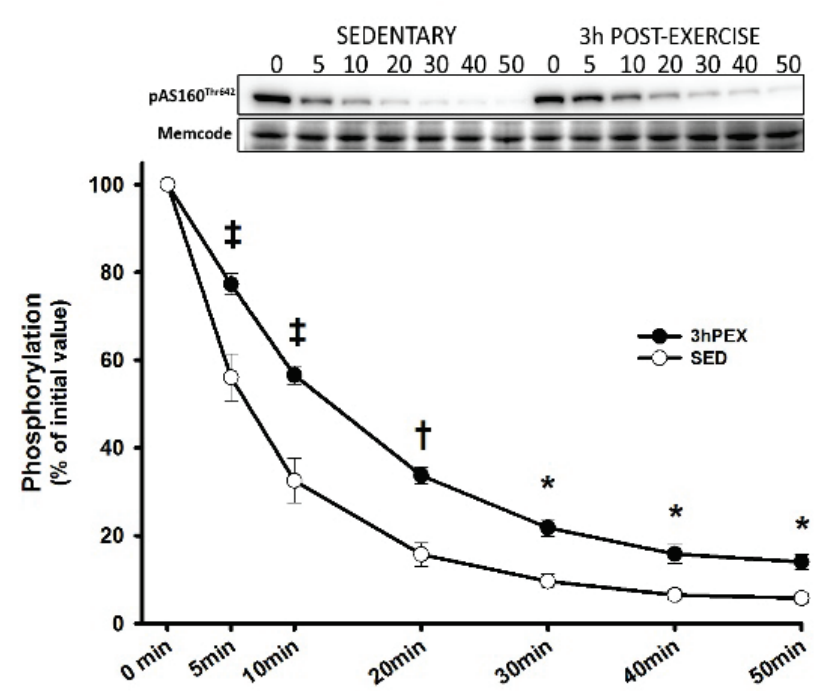

B

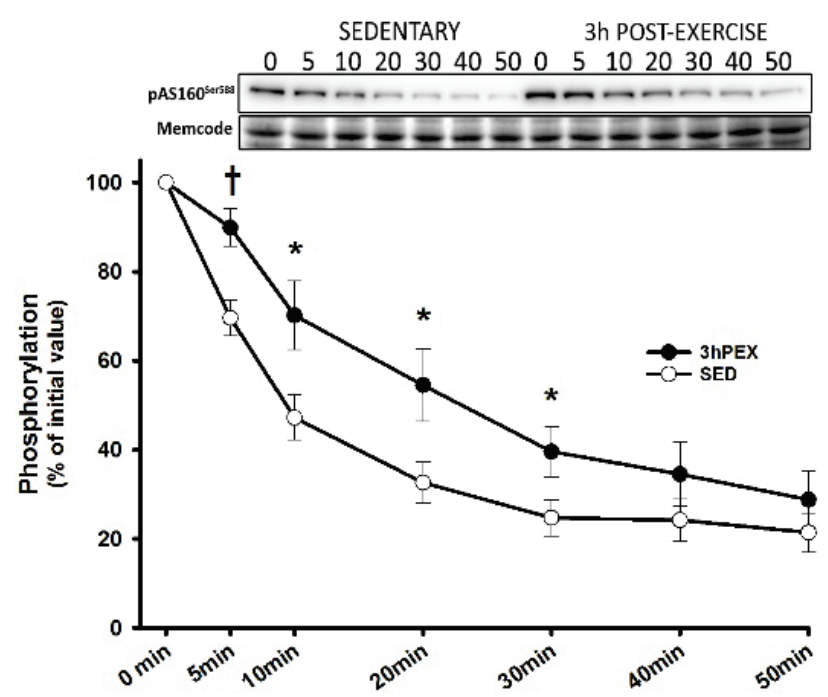

Fig. 2. Lysates prepared from insulin-stimulated (0.6 nM) muscles dissected from Sedentary or $3 \mathrm{~h}$ Post-exercise (3hPEX) rats were incubated for various time-points to assess AS160 dephosphorylation. (A) AS160 ${ }^{\text {Thr642 }}$ phosphorylation differed significantly between Sedentary and 3hPEX groups at 5 and $10 \mathrm{~min}\left({ }^{\mp} \mathrm{P}<0.001\right), 20 \mathrm{~min}\left({ }^{\dagger} \mathrm{P}<0.005\right)$ and 30,40 and $50 \mathrm{~min}$ $(* P<0.05)$. (B) AS160 ${ }^{\text {Ser588 }}$ differed significantly between Sedentary and 3hPEX groups at $5 \mathrm{~min}\left({ }^{+} \mathrm{P}<0.005\right)$ and 10,20 and $30 \mathrm{~min}(* \mathrm{P}<0.05)$. Values are expressed as mean $\pm \mathrm{SEM}$; $\mathrm{n}=11-12$ per treatment.
What are possible mechanisms for the exerciserelated attenuation of AS160 dephosphorylation? Protein phosphorylation depends on the balance between the opposing activities of protein kinases and protein phosphatases, but a disproportionate amount of prior research has focused on kinases rather than phosphatases. Notably, prior studies reporting exercise does not increase Akt activity in insulin-stimulated muscles employed standard Akt enzyme activity assays using muscle lysates (Castorena et al. 2014, Funai et al. 2009). It seems reasonable to suspect that the exercise-related differences in AS160's dephosphorylation in our assay may involve changes in the phosphatase and/or AS160's susceptibility to being dephosphorylated. The dephosphorylation assay used muscle lysates, so the results are probably not attributable to exercise-effects on subcellular localization of AS160 or phosphatases. Because protein phosphatase $1 \alpha \quad(\mathrm{PP} 1 \alpha)$ regulates AS160 $0^{\text {Thr642 }}$ and AS160 $0^{\text {Ser588 }}$ dephosphorylation in muscle (Sharma et al. 2016), it will be important to determine if prior exercise alters PP $1 \alpha$ activity.

\section{Conflict of Interest}

There is no conflict of interest.

\section{Acknowledgements}

Yilin Nie and Carmen Yu provided valuable technical assistance. Supported by a grant from the National Institutes of Health (DK71771).

\section{References}

ARIAS EB, KIM J, FUNAI K, CARTEE GD: Prior exercise increases phosphorylation of Akt substrate of $160 \mathrm{kDa}$ (AS160) in rat skeletal muscle. Am J Physiol Endocrinol Metab 292: E1191-E1200, 2007.

CARTEE GD: Mechanisms for greater insulin-stimulated glucose uptake in normal and insulin-resistant skeletal muscle after acute exercise. Am J Physiol Endocrinol Metab 309: E949-E959, 2015a.

CARTEE GD: Roles of TBC1D1 and TBC1D4 in insulin- and exercise-stimulated glucose transport of skeletal muscle.

Diabetologia 58: 19-30, 2015b. 
CARTEE GD, HOLLOSZY JO: Exercise increases susceptibility of muscle glucose transport to activation by various stimuli. Am J Physiol 258: E390-E393, 1990.

CASTORENA CM, ARIAS EB, SHARMA N, CARTEE GD: Postexercise improvement in insulin-stimulated glucose uptake occurs concomitant with greater AS160 phosphorylation in muscle from normal and insulin-resistant rats. Diabetes 63: 2297-2308, 2014.

CHEN S, WASSERMAN DH, MACKINTOSH C, SAKAMOTO K: Mice with AS160/TBC1D4-Thr649Ala knockin mutation are glucose intolerant with reduced insulin sensitivity and altered GLUT4 trafficking. Cell Metab 13: 68-79, 2011.

FUNAI K, SCHWEITZER GG, SHARMA N, KANZAKI M, CARTEE GD: Increased AS160 phosphorylation, but not TBC1D1 phosphorylation, with increased postexercise insulin sensitivity in rat skeletal muscle. Am J Physiol Endocrinol Metab 297: E242-E251, 2009.

HANSEN PA, GULVE EA, HOLLOSZY JO: Suitability of 2-deoxyglucose for in vitro measurement of glucose transport activity in skeletal muscle. J Appl Physiol 76: 979-985, 1994.

PEHMOLLER C, BRANDT N, BIRK JB, HOEG LD, SJOBERG KA, GOODYEAR LJ, KIENS B, RICHTER EA, WOJTASZEWSKI JF: Exercise alleviates lipid-induced insulin resistance in human skeletal muscle-signaling interaction at the level of TBC1 domain family member 4. Diabetes 61: 2743-2752, 2012.

SHARMA P, ARIAS EB, CARTEE GD: Protein phosphatase 1-alpha regulates AS160 Ser588 and Thr642 dephosphorylation in skeletal muscle. Diabetes 65: 2606-2617, 2016.

WOJTASZEWSKI JF, JORGENSEN SB, FROSIG C, MACDONALD C, BIRK JB, RICHTER EA: Insulin signalling: effects of prior exercise. Acta Physiol Scand 178: 321-328, 2003. 